\title{
Atypical scleromyxedema presenting with cutaneous and cardiovascular manifestations
}

\author{
Sue-Ann Teh' \\ David A Kandiah ${ }^{2}$ \\ 'Department of Health Western \\ Australia, Bunbury Hospital, Bunbury, \\ ${ }^{2}$ School of Psychiatry and Clinical \\ Neurosciences, Faculty of Medicine, \\ Dentistry and Health Sciences, \\ University of Western Australia, \\ Crawley, WA, Australia
}

This article was published in the following Dove Press journal:

International Medical Case Reports Journal

19 September 2016

Number of times this article has been viewed

\begin{abstract}
Scleromyxedema is part of a group of cutaneous mucinoses, characterized by a generalized papular eruption, dermal mucin deposition, and an increase in dermal collagen. This condition can be localized as discrete papular lichen myxedematous skin or as a systemic condition usually associated with paraproteinaemia. To date, there is no unifying treatment and is limited by rarity, small number of case reports, and the lack of randomized controlled trials. We describe the case of a 56-year-old gentleman with features of scleromyxedema who had cutaneous and cardiac involvement, and significant mediastinal lymphadenopathy without monoclonal gammopathy.
\end{abstract}

Keywords: scleromyxedema, heart failure, dermal mucin

\section{Introduction}

Scleromyxedema is a rare chronic cutaneous fibromucinous disorder of unknown etiology, commonly associated with monoclonal gammopathy, usually immunoglobulin G with lambda light chains. ${ }^{1}$ Dubreuilh first described this in $1906 .{ }^{2}$ This was further defined by Rongioletti and Rebora in 2001 as characterized by generalized papular and sclerodermoid eruption, mucin deposition, fibroblast proliferation and fibrosis, monoclonal gammopathy, and the absence of thyroid disorder. ${ }^{3}$

\section{Case}

The patient provided written informed consent for the publication of this paper and accompanying images. We report a case of a 56-year-old man who was referred by his general practitioner for assessment and investigations of dyspnea and bilateral lower limb swelling. This started after a tooth extraction for an abscess 2 months previously. Soon after, he developed lower limb swelling and painful lesions consistent but not diagnostic of erythema nodosum. He did not report any fever, night sweats, weight loss, or altered bowel habit. Initially, his condition was attributed to an immunological reaction to a tooth abscess with likely streptococcal bacteremia causing the systemic

Correspondence: David A Kandiah School of Psychiatry and Clinical Neurosciences, Faculty of Medicine, Dentistry and Health Sciences, University of Western Australia, PO Box 1293, Bondi Junction, NSW 1355, Australia Tel +6 I 4488 0 I | 4 I

Fax +61290341241

Email davidkandiah@doctor.com skin eruptions. He was prescribed a course of Augmentin Duo Forte 875/125 mg bid. Antistreptolysin titers were negative. The course of antibiotics settled the tooth infection but his dyspnea and lower limb edema worsened with associated skin tethering.

His past medical history was of benign heart murmurs diagnosed at the age of 2 . He was not on any regular medications. He did not smoke but admitted to previous heavy alcohol intake, but currently limited to one beer per day. 


\section{Physical examination}

His pulse was $86 / \mathrm{min}$ and regular and blood pressure was $150 / 90$. There were a few $2-5 \mathrm{~mm}$ lesions with the appearance of lichenoid papules, which were tender over his abdomen and lower limbs. He had tight, tethered, and thickened skin up to his abdomen. Closer inspection of his skin showed that the skin was thickened in a linear distribution with the papules being skin-colored with scattered hyperpigmentation (Figure 1). The skin on his chest and arms was not affected. He had signs of biventricular heart failure. His heart sounds were dual with soft systolic murmurs. Ascites were present.

\section{Investigations}

Full blood count and renal function were normal. Liver function test showed a mild cholestatic picture consistent with hepatic congestion. Serum and urine protein electrophoresis and immunoglobulin-free light chain assays were normal. Thyroid function tests and angiotensin converting enzyme levels were normal. Autoantibody screening was negative. His C-reactive protein was $38 \mathrm{mg} / \mathrm{L}(<5)$ with a normal erythrocyte sedimentation rate of $12 \mathrm{~mm} / \mathrm{h}$. Troponin I and creatinine kinase were both within normal limits. B type natriuretic peptide was $468 \mu \mathrm{g} / \mathrm{L}(<250)$. His chest X-ray showed marked globular cardiomegaly and interstitial pulmonary edema. Echocardiogram revealed a moderately dilated left ventricle with global impairment of systolic function with an estimated ejection fraction of $20 \%$. There was a small to moderate pericardial effusion but no echo evidence of pericardial tamponade or constriction. Computed tomography of chest/abdomen/pelvis showed significant mediastinal lymphadenopathy with mildly enlarged abdominal and inguinal lymph nodes.

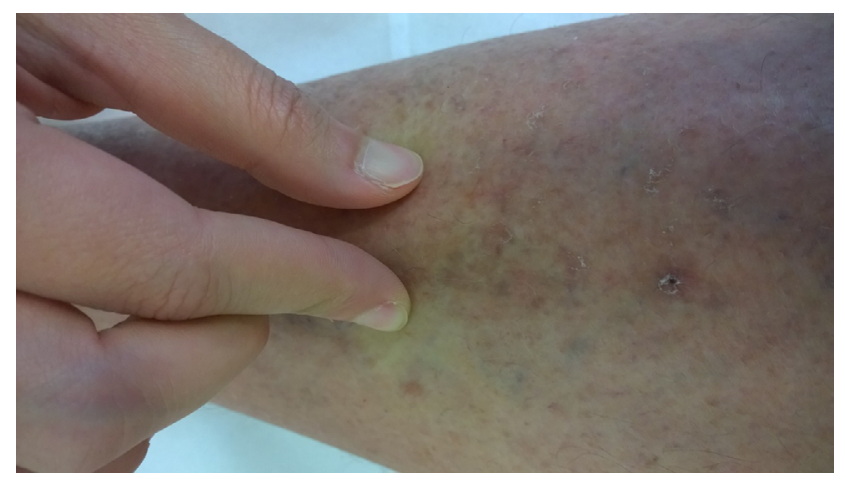

Figure I At presentation, there was linear thickening of skin of lower limbs with small discrete papules and areas of hyperpigmentation.

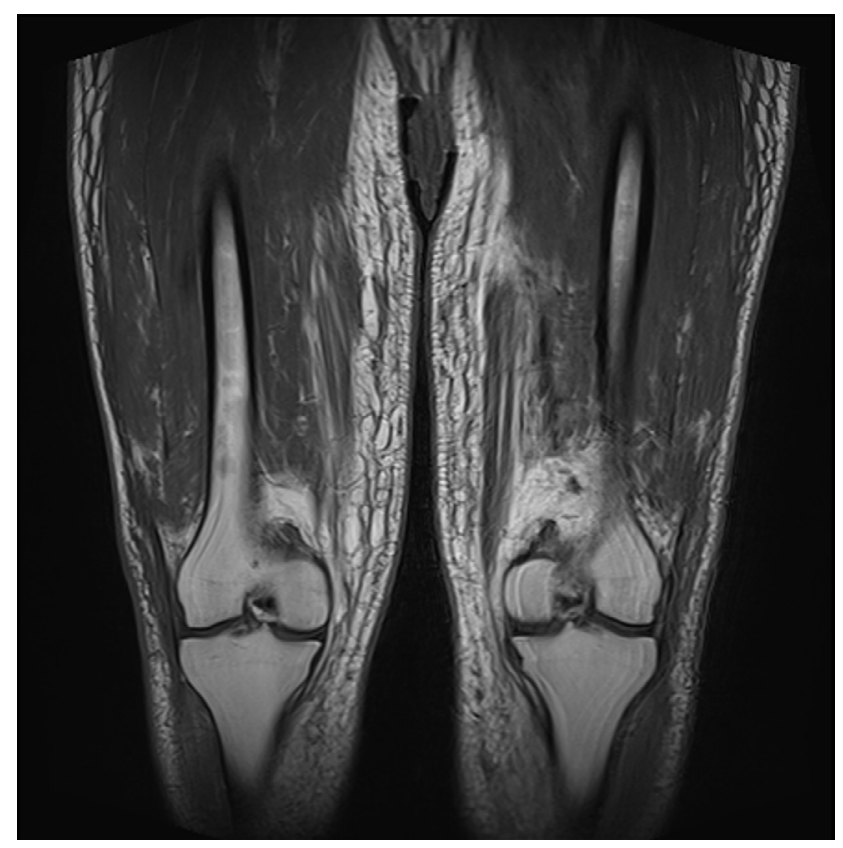

Figure 2 Magnetic resonance imaging of pelvis and legs showed bilateral lower limb subcutaneous edema with prominence of the dermal thickness and patchy tethering with increased T2 signal of the quadriceps and adductor muscle groups.

Magnetic resonance imaging of pelvis and legs showed widespread lower abdominal trunk, pelvic girdle, and bilateral lower limb subcutaneous edema with prominence of the dermal thickness (Figure 2). There was associated patchy tethering with increased $\mathrm{T} 2$ signal of the quadriceps, hamstring, and adductor muscle groups. Inguinal and external iliac lymph nodes were mildly enlarged. There was no hip or knee joint synovitis or effusions seen.

\section{Clinical management}

The patient was started on diuretics with frusemide $40 \mathrm{mg}$ bid, and spironolactone $25 \mathrm{mg}$ daily, and carvedilol $3.125 \mathrm{mg}$ daily for heart failure and fluid restricted to $1.5 \mathrm{~L} /$ day. His heart failure improved with this treatment and he lost $9 \mathrm{~kg}$ of weight during the hospital admission in the first 5 days. Skin biopsy was taken from bilateral legs and abdomen. This showed compact orthokeratotic hyperkeratosis overlying mildly acanthotic epidermis. There was an increase in fibroblastic cells and interstitial connective tissue mucin in the dermis associated with perivascular lymphocytic infiltrate. There was thickening of the dermal collagen bundles with loss of adipose tissues around the eccrine glands (Figure 3A-D). The earlier findings were compatible with scleromyxedema. ${ }^{4}$ After the skin biopsy, he was encouraged to massage his skin regularly with sorbolene and vitamin E cream to improve vascular and lymphatic flow. 
A

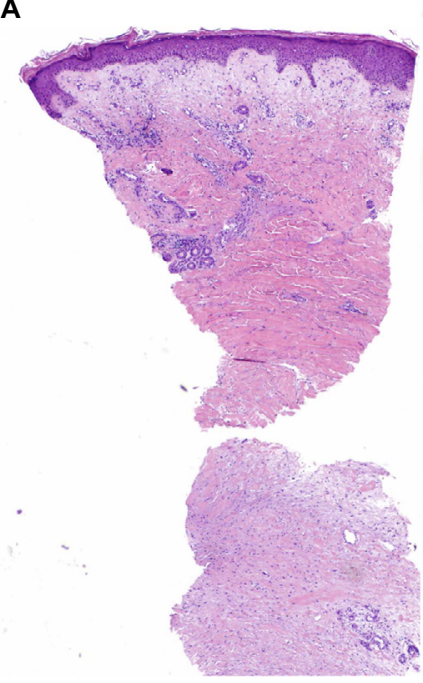

C

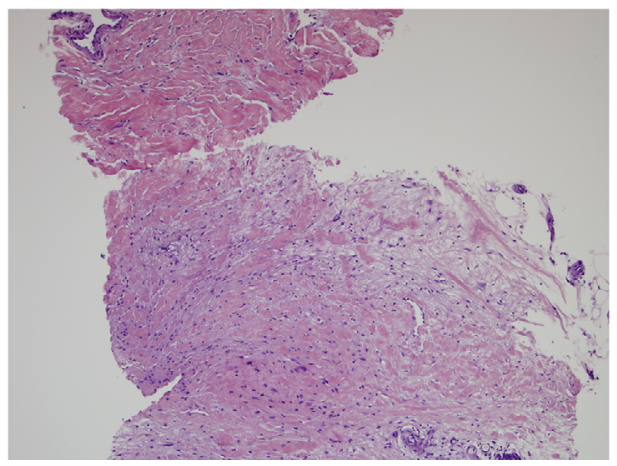

B

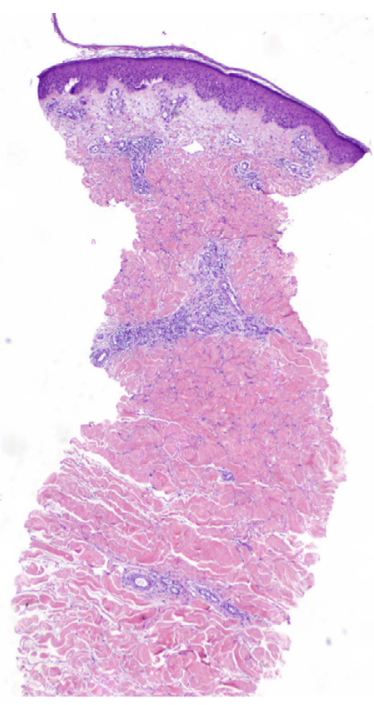

D

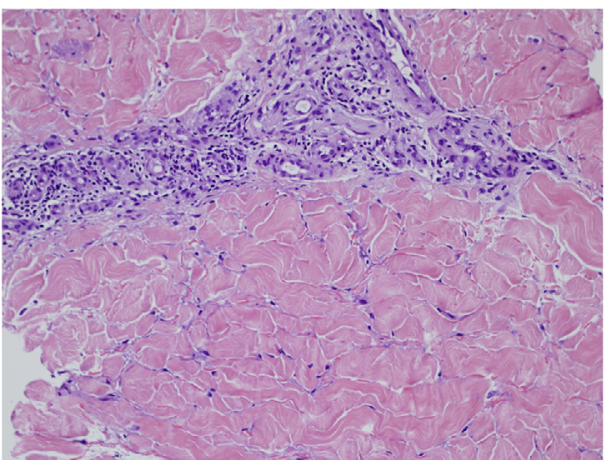

Figure 3 (A) Skin biopsy - leg ( $\times 40$ magnification), (B) skin biopsy - abdomen ( $\times 40$ magnification), (C) deep skin biopsy - leg ( $\times 100$ magnification), and (D) perivascular and thickened collagen - abdomen $(\times 200$ magnification).

Note: The histology shows normal epidermis with proliferation of angular fibroblasts in the reticular dermis accompanied by disorganized collagen fibres (A-C). Increased interstitial connective tissue mucin in the dermis associated with perivascular lymphocytic infiltrate, there was thickening of the dermal collagen bundles with loss of adipose tissues around the eccrine glands (D).

\section{Progress over next 12 months}

He subsequently lost another $8 \mathrm{~kg}$ in 8 weeks and went back to his normal average weight. His creatinine remained normal at 67 $\mu \mathrm{mol} / \mathrm{L}$ and his estimated glomerular filtration rate (eGFR) was $>90 \mathrm{~mL} / \mathrm{min} / 1.73 \mathrm{~m}^{2}$. Frusemide was reduced to $40 \mathrm{mg} /$ day but he remained on the same dose of spironolactone and carvedilol. Four weeks later, he became asymptomatic from congestive cardiac failure with no dyspnea, ascites, or peripheral edema. He developed two further episodes of a linear nontender papular mucinous rash in both his upper and lower limbs over the next 6 months with no flare of heart failure. His creatinine remained normal with an eGFR of $85 \mathrm{~mL} / \mathrm{min} / 1.73 \mathrm{~m}^{2}$. His extractable nuclear antigen became equivocal from a previously negative result. His other autoantibodies were negative. The computed tomography scan of his chest and abdomen showed a significant improvement of his fluid retention. The ascites and mediastinal lymphadenopathy had resolved and the pericardial effusion had significantly reduced. Clinically, his lower limb skin was less tethered (Figure 4). Repeat echocardiogram revealed a mildly dilated left ventricle with an overall mild impairment of systolic function with an estimated ejection fraction of $45 \%$.

\section{Discussion}

Scleromyxedema has been further subclassified by Rongioletti in 2006 into three categories: generalized form, localized form, including papular and nodular types, and atypical forms, which included scleromyxedema without monoclonal gammopathy. ${ }^{1}$ The skin eruption is commonly described as papular mucinosis or waxy papules with a predilection for sun exposed areas. This patient worked consistently outside in the sun. The firm papules can converge into indurated plaques, causing marked sclerosis, skin induration, and decreased 


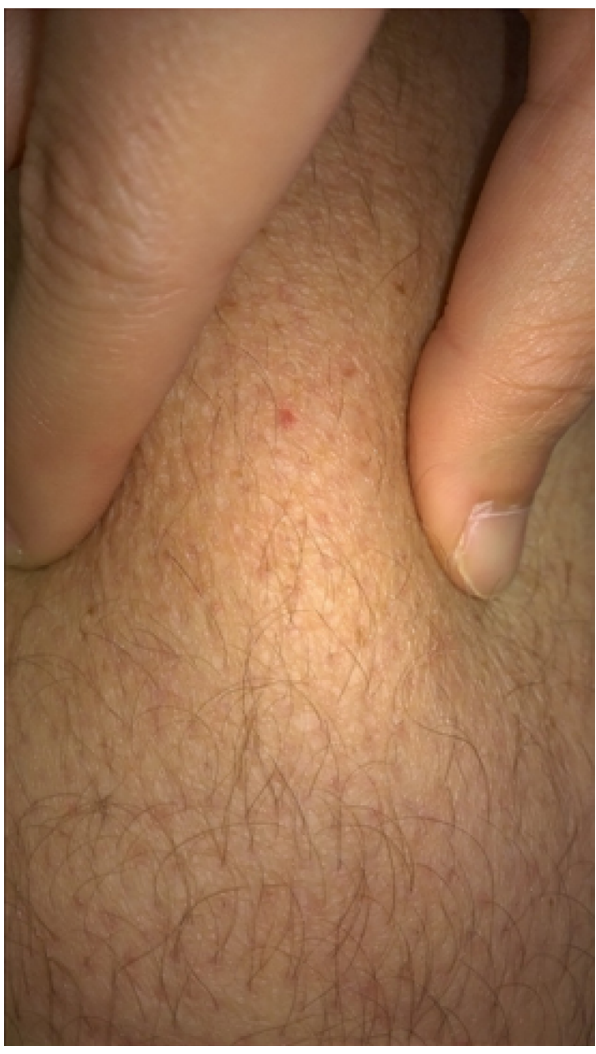

Figure 4 Progress at 9 months: spontaneous regression of skin changes.

joint mobility in the generalized form of scleromyxedema. The mucous membranes and scalp are usually spared as was the situation with this patient. Extra-cutaneous manifestations include neurological, gastrointestinal, respiratory, cardiovascular, rheumatological, renal, and hematological complications. ${ }^{3}$ In localized form, sclerotic features, systemic involvement, and monoclonal gammopathy are absent.

Our patient has an atypical form of scleromyxedema with cutaneous and cardiac involvement with prominent mediastinal lymphadenopathy. Cutaneous manifestations were the most common findings in scleromyxedema. Absence of paraproteinaemia has been described. ${ }^{3}$ A literature search of cutaneous manifestations of scleromyxedema showed that some patients exhibited red-brown discoloration of the involved skin. ${ }^{5}$ Scleromyxedema with cardiac involvement, for instance congestive cardiomyopathy, myocardial infarction, and inflammatory cardiomyopathy, has been previously reported. ${ }^{5} \mathrm{~A}$ cardiac biopsy could have confirmed myocardial involvement in this patient. This was considered too invasive but would have been performed if he had not responded adequately to cardiac failure treatment. As he is being monitored, this may be considered in future if his cardiac failure becomes refractory. In the absence of other causes of heart failure, normal troponins, and the relatively low B type natriuretic peptide, the cardiac failure was considered to be due to early myocardial fibrotic changes. Mucin deposition in the myocardium and heart vessels was noted in autopsy findings. ${ }^{6}$ Enlarged mediastinal lymphadenopathy was uncommon and was observed in a patient associated with monoclonal gammopathy.

As our patient clinically improved with heart failure treatment, we opted to monitor him rather than commence the patient on immunological treatment for scleromyxedema. The current suggested treatments are based on anecdotal case studies and case series. Suggested treatments include systemic steroids, ${ }^{5}$ plasmapheresis, ${ }^{8}$ interferon alpha, ${ }^{9}$ stem cell transplantation, ${ }^{10}$ intravenous immunoglobulin, ${ }^{11}$ thalidomide, ${ }^{12}$ bortezomib, ${ }^{5,12}$ and chemotherapy. ${ }^{12}$

However, the side effects limit the use of many options. Studies show dramatic results with intravenous immunoglobulin as primary therapy ${ }^{11}$ but the effect may be short lasting as predicted from its mechanism of action. This requires regular maintenance and can be expensive. In our patient, the course of his disease has been favorable so far with spontaneous regression of skin changes.

\section{Conclusion}

In conclusion, scleromyxedema is rare and can be chronic and progressive with high morbidity and mortality. Hence, long-term follow-up of such patients is pivotal. The diversity of scleromyxedema clinical presentations means that clinicians should be aware of this possible diagnosis.

\section{Disclosure}

The authors report no conflicts of interest in this work.

\section{References}

1. Rongioletti F. Lichen myxedematosus (papular mucinosis): new concepts and perceptives for an old disease. Semin Cutan Med Surg. 2006;25(2):100-104.

2. Dubreuilh W. Fibromes miliaires folliculaires: sclerodermie consecutive. Arch Dermatol Syphilol. 1906;7:569-570.

3. Rongioletti F, Rebora A. Updated classification of papular mucinosis, lichen myxedematosus, and scleromyxedema. J Am Acad Dermatol. 2001;44(2):273-281.

4. Fernandez-Flores A, Gatica-Torres M, Ruelas-Villavicencio AL, Saeb-Lima M. Morphological clues in the diagnosis of sclerodermiform dermatitis. Am J Dermapathol. 2014;36(6):449-464.

5. Rongioletti F, Merlo G, Cinotti E, et al. Scleromyxedema: a multicenter study of characteristics, comorbidities, course, and therapy in 30 patients. J Am Acad Dermatol. 2013;69(1):66-72.

6. Loggini B, Pingitore R, Avvenente A, Giuliano G, Barachini P. Lichen myxedematosus with systemic involvement: clinical and autopsy findings. J Am Acad Dermatol. 2001;45(4):606-608.

7. Pomann JJ, Rudner EJ. Scleromyxedema revisited. Int $J$ Dermatol. 2003;42(1):31-35. 
8. MacFarlane AW, Davenport A, Verbov JL, Goldsmith HJ. Scleromyxoedema - successful treatment with plasma exchange and immunosuppression. Br J Dermatol. 1987;117(5):653-657.

9. Tschen JA, Chang JR. Scleromyxedema: treatment with interferon alfa. J Am Acad Dermatol. 1999;40(2 Pt 2):303-307.

10. Feasel AM, Donato ML, Duvic M. Complete remission of scleromyxedema following autologous stem cell transplantation. Arch Dermatol. 2001;137(8):1071-1072.
11. Blum M., Wigley FM, Hummers LK. Scleromyxedema: a case series highlighting long-term outcomes of treatment with intravenous immunoglobulin (IVIG). Medicine (Baltimore). 2008;87(1):10-20.

12. Ataergin S, Arpaci F, Demiriz M, Ozet A. Transient efficacy of double high-dose chemotherapy and autologous peripheral stem cell transplantation, immunoglobulin, thalidomide, and bortezomib in the treatment of scleromyxedema. Am J Clin Dermatol. 2008;9(4): 271-273.

\section{Publish your work in this journal}

The International Medical Case Reports Journal is an international, peer-reviewed open-access journal publishing original case reports from all medical specialties. Previously unpublished medical posters are also accepted relating to any area of clinical or preclinical science. Submissions should not normally exceed 2,000 words or
4 published pages including figures, diagrams and references. The manuscript management system is completely online and includes a very quick and fair peer-review system, which is all easy to use. Visit http://www.dovepress.com/testimonials.php to read real quotes from published authors.

Submit your manuscript here: https://www.dovepress.com/international-medical-case-reports-journal-journal 